\title{
Application of Quick Switching System-1 with Single sampling Plan as reference plan through Minimum Sum of Risks in Determining Economic Ordering Policies under Permissible Delay in Payments
}

\author{
K Pradeepa Veerakumari * and H M Aruna ${ }^{1}$ \\ *Assistant Professor, Department of Statistics, Bharathiar University, \\ Coimbatore-641046, Tamil Nadu, India. \\ ${ }^{1} \mathrm{PhD}$ Research Scholar, Department of Statistics, Bharathiar University, \\ Coimbatore-641046, Tamil Nadu, India. \\ *pradeepaveerakumari@buc.edu.in \\ (D) https://orcid.org/0000-0001-6402-3234
}

Received: $16^{\text {th }}$ July 2018 / Revised: $8^{\text {th }}$ Jan 2020/Accepted: $6^{\text {th }}$ March 2020

CIAppStat-SL2014

\begin{abstract}
Conventionally, all Economic Ordering model tacitly assumes that the immediate payment with the shipment of the products. But, in practice, the vendor may allow permissible delay in payments to the buyer. Quality management with minimized cost is the crucial factor for organization's growth. Inspecting $100 \%$ of the products are time-consuming and costly especially when it involves destructive testing or inspection cost is huge. Acceptance sampling plan by attributes provides an effective solution to minimize the cost and consumes less time. Quick Switching System-1with two intensity of inspection is ease to apply as it enables instantaneous switch between normal and tightened inspection depends on the quality of the product. With more reliable products normal inspection is employed and vice versa.QSS-1 plan with minimum sum of risks carries another advantage of reducing the consumer and producer's risk. With the application of the QSS-1 through minimum sum of risks on the EOQ model with permissible delay in payments buyer and vendor gets minimized cost, minimized risk and less time consuming process.
\end{abstract}

Keywords: Quick Switching System-1, Minimum sum of risks, Economic Ordering Quantity, Permissible delay in payments. 


\section{Introduction}

Acceptance sampling or statistical product control adheres to the process of randomly inspecting a sample of products and determines whether to accept the entire lot based on the results or reselling or rejection of the lot, returning to the producer, screening and scraping. American National Standards Institute/American Society for Quality Control Standard A2 (1987) defines acceptance sampling as the not-accept are based on the results of the inspection of samples.

Montogomery (2009) cited that Dodge and Romig in 1928 developed acceptance sampling procedures at Bell Laboratories testing the bullets. It is a product control techniques applied to determine whether the incoming raw materials or outgoing final products fit to the described quality standards. Final products are compiled to form lots or batches in industries. After manufacturing the product it is mandatory to determine their conformity to the admissible specification requirements on the basis of acceptance sampling plans. Periodically, an organization's own output can be submitted to acceptance sampling at different stages of manufacturing such as inspection of raw materials, semi-finished product and terminal production.

A company inspects its final products by implementing one of the three sampling techniques, (i) accepting with zero inspection (ii) $100 \%$ inspection and (iii) acceptance sampling. Acceptance with zero inspection is adopted when the industry has good background of its products. Acceptance of the entire lot with $100 \%$ inspection is undesirable in most of the situations especially when the testing involves destructive or costly. US Military applied acceptance sampling technique in testing of bullets during World War II. Consider a case of inspection of bullets, if every bullet is tested (100\% inspection) earlier, not any of the bullets would be left for shipping. On the contrary, if none of the bullets (zero inspection) were tested may results in potential dangerous malfunctions. Acceptance sampling is a trade-off between $100 \%$ inspection and Zero inspection. It is the effective technique than the $100 \%$ inspection and zero inspection. It safeguards producer against the risk of rejecting a good quality lot as well as consumer against the risk of accepting a bad lot. It is emphasized that the principle of acceptance sampling is to ascertain the course of action i.e. accept or reject the lot, but not to assess the quality of the lot. Acceptance sampling plans yields quality assurance.

According to Duncan (1986), an acceptance sampling plan is appropriate to be carried out when the following circumstances hold; 
(1)
When the inspection cost is huge and the cost rising from the passing of a nonconforming unit is not high. It is possible in some cases that zero inspection at all will be the economical plan.

When 100 percent inspection is tired-some and an attentively worked out sampling plan will yield good or better results. The 100 percent inspection does not mean 100 percent perfect quality, and the percentage of nonconforming items passed may be greater than under a scientifically designed sampling plans.

When inspection is destructive, that is, a situation where inspection is not possible without destroying the article chemically or physically.

When there are large quantities or areas to be examined.

When it is desired to stimulate the maker and/or the buyer. American National Standards Institute (ANSI)/American Society for Quality Control (ASQC) Standard A2(1987) defines acceptance sampling "as the methodology deals with procedures by decisions on the acceptance or nonacceptance are based on the results of the inspection of the samples". Acceptance sampling by attributes deals with the quality characteristics of a product by deciding to accept or reject a lot based on specified criteria. It is the most commonly used acceptance sampling techniques. Acceptance sampling by attributes is performed based on the tangible characteristics such as appearance, colour, feel and taste. It arises from classification of products into categories such as good/bad, smooth/rough, bright/dark and so on. Plans includes Single sampling plans, double sampling plans, multiple sampling plans and item by item sequential sampling plans.

Quick Switching System-1 is simple of all sampling schemes proposed by Romboski (1969). It involves two sampling procedures with switching rules between normal and tightened inspection. Romboski (1969) has presented extensively a system of immediate switching to tightened inspection when the rejection comes under normal inspection and vice versa. Due to rapid switching between normal and tightened plans, this system is referred as Quick Switching System-1(QSS-1). QSS-1(n, $\left.\mathrm{c}_{\mathrm{N}}, \mathrm{c}_{\mathrm{T}}\right)$ consists of two sampling procedures $\left(\mathrm{n}, \mathrm{c}_{\mathrm{N}}\right)$ $\&\left(n, c_{T}\right)$ where $n=$ sample size; $c_{N}=$ acceptance number under normal inspection; $\mathrm{c}_{\mathrm{T}}=$ acceptance number under tightened inspection $\left(\mathrm{c}_{\mathrm{N}}<\mathrm{c}_{\mathrm{T}}\right)$. The probability of acceptance of Quick Switching System-1 is 


$$
\mathrm{P}_{\mathrm{a}}=\frac{\mathrm{P}_{\mathrm{T}}}{\left(1-\mathrm{P}_{\mathrm{N}}\right)+\mathrm{P}_{\mathrm{T}}}
$$

Where,

$\mathrm{P}_{\mathrm{N}}=$ proportions of lots expected to be accepted using $\left(\mathrm{n}, \mathrm{c}_{\mathrm{N}}\right)$.

$\mathrm{P}_{\mathrm{T}}=$ proportions of lots expected to be accepted using $\left(\mathrm{n}, \mathrm{c}_{\mathrm{T}}\right)$. The modus operandi of QSS-1 is

1. At the outset, start using normal inspection with $\mathrm{c}_{\mathrm{N}}$.

2. If a lot is rejected $(\mathrm{d}>\mathrm{c})$, then switch to tightened inspection with $\mathrm{c}_{\mathrm{T}}$.

3. When on the tightened inspection, switch to normal inspection after a lot is accepted $(\mathrm{d}<\mathrm{c})$.

4. Alternate to and fro as imposed by the switching rules.

The analytical efficiency of a sampling plan is acknowledged by its operating characteristic (OC) curve $\mathrm{p}_{\mathrm{a}}$. In the non-Bayesian risk-based design of acceptance sampling plans, two points on the OC curve are generally, described namely $\left(p_{1}, 1-\alpha\right)$ and $\left(p_{2}, \beta\right)$ where $p_{1}=$ acceptable quality level, $p_{2}$ $=$ limiting quality level, $\alpha=$ producer's risk, and $\beta=$ consumer's risk. The sampling plan parameters are decided in order to meet the two point requirement with minimum sample size. The conditions of definitive risks are generally modified to

$$
\mathrm{Pa}\left(\mathrm{p}_{1}\right) \geq 1-\alpha \text { and } \mathrm{Pa}\left(\mathrm{p}_{2}\right) \leq \beta,
$$

where, $\mathrm{Pa}(\mathrm{p})$ is the probability of acceptance for given lot quality $p$. Lamentably, it is unfeasible to concurrently minimize the producer's and consumer's risks without letting n unreasonable large. Though, it is feasible to minimize the sum of producer's and consumer's risks.

Golub (1953) proposed a method for determining a SSP incorporating a minimum sum of producer's risk and consumer's risk for given AQL and LQL. This method facilitates when the sample size $\mathrm{n}$ may be fixed for various economic, administrative or practical purposes. In the study it is also stated the approach for acquiring the acceptance number that minimizes the sum of producer's and consumer's risks or correspondingly the sum of probabilities of classifying the lot of $\mathrm{p}_{1}$ as acceptable quality and classifying the lot of $\mathrm{p}_{2}$ as reject able quality. Mathematically the maximization of the risk may be expressed as

$$
P_{a}(p)=P_{a}\left(P_{1}\right)+\left[1-P_{a}\left(p_{2}\right)\right]
$$

where , $\mathrm{P}_{\mathrm{a}}\left(\mathrm{p}_{1}\right)$ is defined as the probability of accepting the lots of quality $\mathrm{P}_{1}$ and $1-\mathrm{Pa}\left(\mathrm{p}_{2}\right)$ is defined as the probability of rejecting the lots of quality $\mathrm{p}_{2}$. on 
other hand, minimizing the sum of producer's and consumer's risks can be expressed as,

$$
\left[1-P_{a}\left(p_{1}\right)\right]+P_{a}\left(p_{2}\right)
$$

In the study it is also shown that the for fixed sample size $\mathrm{n}$, the acceptance $\mathrm{c}$ can be estimated using the equation (4), which minimizes the sum of the risks to the nearest integer

$$
-\frac{1}{2}+\frac{n}{\left\{\left[\log \frac{p_{2}}{p_{1}} / \log \frac{q_{1}}{q_{2}}\right]+1\right\}}
$$

Where $\mathrm{q}_{1}$ representing 1- $\mathrm{p}_{1}$ and $\mathrm{q}_{2}$ representing 1- $\mathrm{p}_{2}$. Golub also constructed tables postulating the values of acceptance number for different values of $n$ based on the binomial model. The Golub's approach for SSP is advanced by Soundarrajan (1981) under the Poisson model. Soundarajan (1978a,b) formulated the tables for the selection of Chain Sampling Plan of type-1 under the Poisson model and also provided a formulae for i which curtails the sum of producer's risk and consumer's risk for given AQL and LQL with the sample size is fixed. Soundararajan and Govindaraju (1982) also established the ChSP1 plan incorporating minimum sum of risks.

Soundarajan and Govindaraju (1983) constructed tables for the selection of single sampling plan which minimizes sum of risk without fixing the sample under Poisson model. Govindaraju and Subramani (1990) designed selection of SSP by attributes incorporating minimum sum of risks deprived of fixing the size of the sample presuming Poisson model. Subramani (1991) proposed a approach for the selection and construction of tables established under Poisson model for specified $p_{1}, p_{2}, \alpha, \beta$ deprived of presuming that the size of the sample ' $n$ ' is known. Subramani and Haridoss (2012) constructed tables for the selection of Multiple Deferred State (MDS-1 $\left(\mathrm{c}_{1}, \mathrm{c}_{2}\right)$ sampling plans for specified $A Q L$ and LQL incorporating minimum sum of risks by applying Weighted Poisson Distribution. Suresh and Kavithamani (2014) advanced and optimized the different standard sampling plans as reference plans through minimum sum of risks approach.

The greatest responsibility of the organization is not only in the managing quality but also manage inventory judiciously, so they create values. Being suitably prepared is one of the biggest assets in business. Inventory control is the process of ensuring that an organization constantly has the products it requires on hand and that it retains costs as low as possible. In inventory control, Economic Order Quantity is the order quantity that minimizes the total 
cost including holding cost, ordering cost. Drawback of the classic EOQ model is the assumption of immediate payment with the shipment of the product. However, in practice vendor accepts payments under permissible delay. Goyal (1985) proposed EOQ model with permissible delay in payments. In the study, it is computed that the purchase price and selling price are equivalent. The model implicitly assumed that the buyer commences paying a higher interest rate on products in the stock and reimbursement the remaining when the items sold rear end of delaying payment period. Published ago three decades, the study is the pioneer for the enormous studies dealing with diverse permissible delay in payments circumstances. Teng (2002) overhauls the Goyal's assumption of the same cost price and selling price by assuming variant cost price and selling price. Tsao (2010) further enhanced the model by incorporating acceptance sampling and trade credit. Pradeepa Veerakumari and Aruna (2017) developed economic ordering models under the conditions of permissible delay in payments with single sampling plan under the conditions of IPD with three payment priviges. Pradeepa Veerakumari and Aruna (2018) proposed an EOQ model with $\mathrm{c}=0$ single sampling plan with inspection errors. The intent of this paper is to develop mathematical model for EOQ model incorporating Quick Switching System-1 with single sampling plan as reference plan under the conditions of Poisson distribution through minimum sum of risks with permissible delay in payment.

\section{Procedure for selection of Quick Switching System-1 with single sampling plan through minimum sum of risks}

The tables constructed is used to select the acceptance number for specified $p_{1}$ and $\mathrm{p}_{2}$ with minimum sum of producer's and consumer's risks.. Against the predetermined value of the operating ratio $p_{2} / p_{1}$, the table provide the parameters of the sampling plans and the associated producer's and consumer's risks in the table against the product of sample size and acceptable quality level $\left(n p_{1}\right)$. Plan parameters are determined for specific values of $\mathrm{p}_{1}, \mathrm{p}_{2}, \alpha, \beta$ involving the subsequent steps and table:-

1. Enumerate the operating ratio $\mathrm{p}_{2} / \mathrm{p}_{1}$.

2. With the enumerated value of operating ratio, enter table headed by operating ratio which is equal or just smaller than the enumerated ratio.

3. The sampling plan parameters is obtained by proceeding from left to right with the row analyzed in the step2, so that the formulated producer and consumer risks are equal or just less than the desired values. 
4. The sample size is obtained using unity value approach $n=n p_{1} / p_{1}$ and the corresponding Acceptance number for normal and tightened inspection for the desired risk is obtained from the table.

Then the operating procedure for the Quick Switching System-1 with single sampling plan under the conditions of Poisson distribution is followed to make a decision on the lot.

\section{Model Assumptions}

The model is developed under the following assumptions

i. Quick Switching System of type QSS-1 $\left(n, c_{N}, c_{T}\right)$.

ii. The products in the received lot are sold at a discounted rate before the shipment of the new order.

iii. Sampling is done with replacement.

iv. Demand is known and invariable around the year.

v. Replenishment order is instantaneous and infinite.

vi. Only single product inventory is considered.

vii. Lead time is ignored.

viii. In the course of time, the account is unsettled, the generated sales return are deposited in the interest bearing account. At the end of the payment period, the buyer pays of all the products sold, keep profits, starts paying for the interest charges on the products stock piled.

$\mathrm{W}<\mathrm{S}, \mathrm{I}_{\mathrm{e}}<\mathrm{I}_{\mathrm{p}}$. Whereas, $\mathrm{W}$ is the price at which the product is sold to buyer and $S$ is the price that sold back. $I_{e}$ is the Interest earned and $I_{p}$ is the interest paid.

\section{Costs involved and Total cost estimation}

It is consider that the consumer places an order of Q to the producer. The ordering cost is definitive and indicated as $c_{o}$ and Demand rate is indicated as D. if the lot is rejected, it is sold at a discounted rate G per unit. Then the cost of rejecting the lot is GD. The other costs involved in this model are

- Annual Ordering $\cos \mathrm{t}=\frac{C_{o}}{T}$ 
Annual Inventory Holding Cost $=\frac{\mathrm{DTC}_{\mathrm{h}}}{2}$

- $\quad$ Cost of Inspection $=\frac{C_{i} \cdot\left(n p_{1} / p_{1}\right)}{T}=\frac{C_{i} n}{T}$

- Annual Interest Earned is twofold

1.When $\mathrm{T} \geq \mathrm{M}$

$$
\text { Annual Interest Earned }=\frac{\mathrm{S} \cdot \mathrm{I}_{\mathrm{e}} \cdot \mathrm{DM}^{2}}{2 \mathrm{~T}}
$$

2. When $\mathrm{T} \leq \mathrm{M}$

$$
\text { Annual Interest Earned }=\frac{\mathrm{SI}_{\mathrm{e}} \cdot \mathrm{DT}}{2}+\mathrm{S} \cdot \mathrm{I}_{\mathrm{e}} \cdot \mathrm{D}(\mathrm{M}-\mathrm{T})
$$

- Annual Interest Paid

1. When $\mathrm{T} \geq \mathrm{M}$

$$
\text { Annual Interest paid }=\frac{W D \cdot I_{p} \cdot(T-M)^{2}}{T}
$$

2. When $\mathrm{T} \leq \mathrm{M}$

Annual Interest charge $=0$. In this case, no interest charge is paid for the items.

If a received lot is rejected after the inspection of $\mathrm{n}$ samples (sample size), then the consumer reorder the lot. If the received lot is also rejected then the consumer again reorders the lot inspect the items using the tightened acceptance number.The process is continued until a lot is accepted. Then the expected total cost becomes, 
- When $\mathrm{T} \geq \mathrm{M}$,

$\mathrm{E}\left(\mathrm{TC}_{1}\right)=$
$\mathrm{P}_{\mathrm{a}} \sum_{\mathrm{x}=0}^{\infty}\left[(1+\mathrm{x})\left(\frac{\mathrm{c}_{\mathrm{o}}}{\mathrm{T}}+\frac{\mathrm{c}_{\mathrm{i}} \cdot \mathrm{n}}{\mathrm{T}}\right)-\mathrm{xKD}+\frac{\mathrm{DTc}_{\mathrm{h}}}{2}-\frac{\text { S.I }_{\mathrm{e}} \cdot \mathrm{DM}^{2}}{2 \mathrm{~T}}+\frac{\mathrm{W} \cdot \mathrm{D} \cdot \mathrm{I}_{\mathrm{p}}(\mathrm{T}-\mathrm{M})^{2}}{2 \mathrm{~T}}\right],\left(1-\mathrm{P}_{\mathrm{a}}\right)^{\mathrm{x}}$

It can be rewritten as,

$$
\begin{aligned}
& \mathrm{E}\left(\mathrm{TC}_{1}\right)=\mathrm{P}_{\mathrm{a}} \sum_{\mathrm{x}=0}^{\infty}(1+\mathrm{x})\left(\frac{\mathrm{c}_{\mathrm{o}}}{\mathrm{T}}+\frac{\mathrm{c}_{\mathrm{i}} \cdot \mathrm{n}}{\mathrm{T}}\right)\left(1-\mathrm{P}_{\mathrm{a}}\right)^{\mathrm{x}}-\sum_{\mathrm{x}=0}^{\infty} \mathrm{x}\left(1-\mathrm{P}_{\mathrm{a}}\right)^{\mathrm{x}} \mathrm{GD}+ \\
& \sum_{\mathrm{x}=0}^{\infty}\left(1-\mathrm{P}_{\mathrm{a}}\right)^{\mathrm{x}}\left(\frac{\mathrm{DTc} \mathrm{c}_{\mathrm{h}}}{2}-\frac{\text { S.I } \mathrm{I}_{\mathrm{e}} \cdot \mathrm{DM} \mathrm{M}^{2}}{2 \mathrm{~T}}+\frac{\text { W.D. } \mathrm{I}_{\mathrm{p}}(\mathrm{T}-\mathrm{M})^{2}}{2 \mathrm{~T}}\right)
\end{aligned}
$$

The results of this series expansion are converging,

$$
\begin{aligned}
& \sum_{x=0}^{\infty}\left[(1+x)\left(1-P_{a}\right)^{x}\right]=\frac{1}{P_{a}^{2}} \\
& \sum_{x=0}^{\infty} x\left(1-P_{a}\right)^{x}=\frac{1-P_{a}}{P_{a}^{2}} \\
& \sum_{x=0}^{\infty}\left(1-P_{a}\right)^{x}=\frac{1}{P_{a}}
\end{aligned}
$$

By substituting the values obtained from eqn 14 to16 in eqn 13, then the expected total cost function becomes,

$$
\mathrm{E}\left(\mathrm{Tc}_{1}\right)=\left(\begin{array}{l}
\left(\frac{\mathrm{C}_{\mathrm{o}}}{\mathrm{T}}+\frac{\mathrm{C}_{\mathrm{i}} \cdot \mathrm{n}}{\mathrm{T}}\right) \frac{1}{\left(\mathrm{P}_{\mathrm{a}}\right)}-\frac{\mathrm{GD}\left(\left(1-\mathrm{P}_{\mathrm{a}}\right)\right.}{\mathrm{P}_{\mathrm{a}}}+ \\
\frac{\mathrm{DTC}_{\mathrm{h}}}{2}-\frac{\text { S.I } \mathrm{I}_{\mathrm{e}} \cdot \mathrm{DM}^{2}}{2 \mathrm{~T}}+\frac{\text { W.D.I. } \mathrm{I}_{\mathrm{p}}(\mathrm{T}-\mathrm{M})^{2}}{2 \mathrm{~T}}
\end{array}\right)
$$

Similarly, the expected total cost $\mathrm{E}\left(\mathrm{Tc}_{2}\right)$, when $\mathrm{T} \leq \mathrm{M}$ is also obtained.

$$
\mathrm{E}\left(\mathrm{Tc}_{2}\right)=\left(\frac{\mathrm{C}_{\mathrm{o}}}{\mathrm{T}}+\frac{\mathrm{C}_{\mathrm{i}} \mathrm{n}}{\mathrm{T}}\right) \frac{1}{\mathrm{P}_{\mathrm{a}}}-\frac{\mathrm{GD}\left(1-\mathrm{P}_{\mathrm{a}}\right)}{\mathrm{P}_{\mathrm{a}}}+\frac{\mathrm{DTC}_{\mathrm{h}}}{2}-\frac{\text { S.I }_{\mathrm{e}} \cdot \mathrm{DT}}{2}-\mathrm{S} . \mathrm{I}_{\mathrm{e}} \mathrm{D}(\mathrm{M}-\mathrm{T})
$$




\section{Theorem on determination of optimal replenishment cycle time and associated least possible cost:}

i. If $\Delta-\mathrm{DM}^{2}\left(\mathrm{C}_{\mathrm{h}}+\mathrm{S} . \mathrm{I}_{\mathrm{e}}\right) \mathrm{P}_{\mathrm{a}}>0$, then the optimal replenishment cycle time is $\mathrm{T}_{1}{ }^{*}$, associated with the least possible cost.

ii. If $\Delta-\mathrm{DM}^{2}\left(\mathrm{C}_{\mathrm{h}}+\mathrm{S} . \mathrm{I}_{\mathrm{e}}\right) \mathrm{P}_{\mathrm{a}}<0$, then the optimal replenishment cycle time is $\mathrm{T}_{2}{ }^{*}$, associated with the least possible cost.

iii. If $\Delta-\mathrm{DM}^{2}\left(\mathrm{C}_{\mathrm{h}}+\mathrm{S} . \mathrm{I}_{\mathrm{e}}\right) \mathrm{P}_{\mathrm{a}}=0$, then the optimal replenishment cycle time is $\mathrm{T}_{1}{ }^{*}=\mathrm{T}_{2}{ }^{*}$, associated with the least possible cost.

\section{Proof:}

The optimal solution for replenishment cycle time for $\mathrm{Tc}_{1}, \mathrm{Tc}_{2}$, is obtained by equating the first order derivative of $\mathrm{Tc}_{1}, \mathrm{Tc}_{2}$ to zero respectively. The respective optimum replenishment cycle time is obtained as

$$
\begin{aligned}
& \mathrm{T}_{1}^{*}=\sqrt{\frac{2\left(\mathrm{C}_{\mathrm{o}}+\mathrm{C}_{\mathrm{i}} \cdot \mathrm{n}\right)+\mathrm{DM}^{2}\left(\mathrm{~W} \cdot \mathrm{I}_{\mathrm{p}}-{\left.\mathrm{S} . \mathrm{I}_{\mathrm{e}}\right) \mathrm{P}_{\mathrm{a}}}_{\mathrm{D}\left(\mathrm{C}_{\mathrm{h}}+\mathrm{W} \cdot \mathrm{I}_{\mathrm{p}}\right) \mathrm{P}_{\mathrm{a}}}\right.}{\mathrm{T}_{2}^{*}}=\sqrt{\frac{2\left(\mathrm{C}_{\mathrm{o}}+\mathrm{C}_{\mathrm{i}} \cdot \mathrm{n}\right)}{\mathrm{D}\left(\mathrm{C}_{\mathrm{h}}+\mathrm{W} \cdot \mathrm{I}_{\mathrm{p}}\right) \mathrm{P}_{\mathrm{a}}}}}
\end{aligned}
$$

It is clearly evident from the results of the eqn 18 and 19, that the second order derivative of the $\mathrm{Tc}_{1}$ and $\mathrm{Tc}_{2}$ are also greater than zero. By substituting the value of $\mathrm{T}_{1}{ }^{*}$ in the inequality $\mathrm{T}>\mathrm{M}$ with $\Delta=2\left(\mathrm{C}_{\mathrm{o}}+\mathrm{C}_{\mathrm{i}} \cdot \mathrm{n}\right)$, the optimal condition for $\mathrm{T}_{1}{ }^{*}$

$$
\Delta+\mathrm{DM}^{2}\left(\mathrm{C}_{\mathrm{h}}+\mathrm{S}_{\mathrm{e}} \mathrm{I}_{\mathrm{e}}\right) \mathrm{P}_{\mathrm{a}}>0
$$

is obtained. Similarly, by substituting the value of $\mathrm{T}_{2}{ }^{*}$ in the inequality $\mathrm{T}<\mathrm{M}$, the optimal condition for $\mathrm{T}_{2}{ }^{*}$

$$
\Delta+\mathrm{DM}^{2}\left(\mathrm{C}_{\mathrm{h}}+\text { S.I }_{\mathrm{e}}\right) \mathrm{P}_{\mathrm{a}}<0
$$

If $\mathrm{T}_{1}{ }^{*}=\mathrm{T}_{2}{ }^{*}$, then the optimal condition is

$$
\Delta+\mathrm{DM}^{2}\left(\mathrm{C}_{\mathrm{h}}+\text { S.I }_{\mathrm{e}}\right) \mathrm{P}_{\mathrm{a}}=0
$$

From the eqn 21 to 23 , the proof is determined for the theorem. 
To illustrate the results, proposed method is applied to hypothetical numerical examples where the associated costs and parameters are, $\mathrm{C}_{0}=\$ 50, \mathrm{C}_{\mathrm{i}}=\$ 0.1$ perunit; $\mathrm{C}_{\mathrm{h}}=0.5 ; \mathrm{D}=1000 ; \mathrm{G}=0.05 ; \mathrm{W}=5$ per unit $; \mathrm{S}=7$ per unit $\mathrm{I}_{\mathrm{e}}=.10 ; \mathrm{I}_{\mathrm{p}}=.15 ; \mathrm{M}=0.2 ; \mathrm{p}=0.02$ in appropriate units. By applying the theorem, for various values of $\mathrm{p}_{2} / \mathrm{p}_{1}, \mathrm{np}_{1}$ the optimal replenishment cycle interval associated with the least cost is derived.

Table 1: Expected Total cost for different values of $\mathrm{p}_{2} / \mathrm{p}_{1}, \mathrm{np}_{1}$

\begin{tabular}{|l|l|l|l|l|l|l|c|}
\hline $\mathrm{p}_{2} / \mathrm{p}_{1}$ & $\mathrm{np}_{1}$ & $\mathrm{~N}$ & $\mathrm{c}_{\mathrm{N}}, \mathrm{c}_{\mathrm{T}}$ & $\alpha$ & $\beta$ & $\mathrm{T}^{*}$ & $\mathrm{TC}^{*}$ \\
\hline 2.0 & 1.0 & 50 & 0,2 & 3 & 10 & $\mathrm{~T}_{1}{ }^{*}=0.3553$ & 509.07 \\
\hline 2.0 & 2.0 & 100 & 0,4 & 0 & 0 & $\mathrm{~T}_{1}{ }^{*}=0.3552$ & 616.77 \\
\hline 2.0 & 3.0 & 150 & 0,7 & 1 & 1 & $\mathrm{~T}_{1}{ }^{*}=0.4439$ & 698.77 \\
\hline 2.0 & 4.0 & 200 & 0,9 & 2 & 3 & $\mathrm{~T}_{1}{ }^{*}=0.4625$ & 756.20 \\
\hline 2.0 & 5.0 & 250 & 0,13 & 0 & 1 & $\mathrm{~T}_{1}{ }^{*}=0.4822$ & 797.68 \\
\hline 2.0 & 6.0 & 300 & 0,15 & 1 & 0 & $\mathrm{~T}_{1}{ }^{*}=0.4993$ & 833.54 \\
\hline 2.0 & 7.0 & 350 & 2,16 & 0 & 0 & $\mathrm{~T}_{1}{ }^{*}=0.5074$ & 853.37 \\
\hline 2.0 & 8.0 & 400 & 3,18 & 0 & 0 & $\mathrm{~T}_{1}{ }^{*}=0.5069$ & 857.95 \\
\hline
\end{tabular}

\section{Conclusion}

It is noted that the as a result of permission delay in payment the total expected cost reduces. The proposed study focuses on deriving the cost model which substantially pertains to the new procedure in designing \& evaluation of Quick Switching System-1 with single sampling plan as reference plan indexed through the producer's and consumer's risk on economic ordering policies with permissible delay in payments. It not only aids in attaining the minimum cost but also aids in attaining associated minimum sum of risks. The proposed study would be a valuable addition to the literature and useful to the quality control and inventory control practitioners. 


\section{References}

1. Golub.A(1953).Designing Single Sampling Inspection Plans when the Sample size is fixed.Journal of American Statistical Association,48:278-288.

2. Govindaraju.K. and Subramani.K.(1990).Selection of Multiple Deffered State MDS-1 Sampling plans for given Acceptable and Limiting Quality Levels involving Minimum risks. Journal of Applied Statistics, 17:431-434.

3. Goyal.S.K.(1985).Economic Order Quantity under Conditions of Permissible Delay in Payments. Journal of operational research society, 36:335-338.

4. PradeepaVeerakumari.K,Aruna.H.M.(2017).Application of SSP for determination of influence over trade credit with payment choice. .International Journal of pure and Applied Mathematics, 117(13):193201.

5. PradeepaVeerakumari.K,Aruna.H.M.(2018). Determination of Economic Ordering Policies under Trade credit with Application of Zero Acceptance number Single Sampling by Attributes involving Destructive Testing, Inspection Errors. International Journal of Scientific Research in Mathematical and Statistical Sciences,5(3):7984.

6. Romboski L D. (1969). An Investigation of Quick Switching Acceptance Sampling Systems.Ph.D Thesis. Rutgers-The State University New Brunswick: New Jersey.

7. Soundararajan.V. (1978 a, b).Procedures and Tables for Construction and Selection of Chain Sampling Plan(chSP-1).Part I and II.Journal of Quality Technology,10(2):56-60 and 10(3):99-103.

8. Soundararajan.V.(1981). Sampling Inspection Plans When the Sample Size is Fixed. Journal of Madras University, Section B.44: 9-19.

9. Soundararajan.V. and Govindaraju.K.(1982).A Note on Designing Chain Sampling Plans ChSP-1.The QR Journal,9:121-123.

10. Soundararajan.V. and Govindaraju.K.(1983). A Note on Designing Single Sampling Plans.IAPQR Transactions,8:37-41. 
11. Subramani.K.(1991).Studies on Designing Attribute Acceptance Sampling Plans with emphasis on Chain Sampling Plans. PhD thesis, Bharathiar University, Coimbatore, Tamil Nadu, India.

12. Subramani.K and Haridoss.V.(2012).Selection of Multiple Deferred State MDS-1 Sampling Plan for given Acceptable Quality Level and Limiting Quality Level involving minimum sum of risks using weighted Poisson Distribution.International Journal for Quality Research,10:939-949.

13. Suresh.K.K and Kavithamani.M(2013).Selection of SkSP-V with STDS as reference plan involving minimum sum of risks.Journal of Indian Academy of Mathematics, 35:119-130.

14. Teng.J.T.(2002).On the Economic Order Quantity under Conditions of Permissible Delay in Payments. Journal of operational research society,53: 915-918.

15. Tsao.Y.C. (2010).Optimal Ordering policy under Acceptance Sampling plan and trade credit financing. Transaction E: Industrial Engineering, 17:120-128.

\section{Appendix}

Table 2.Parameteric values of $\mathrm{c}_{\mathrm{N}}, \mathrm{c}_{\mathrm{T}}$ for integral values through minimum sum

\begin{tabular}{|c|c|c|c|c|c|c|c|c|c|c|}
\hline $\begin{array}{l}n p_{1} \\
p_{2} \times p \\
1\end{array}$ & $\begin{array}{l}0.5 \\
0\end{array}$ & 1.0 & 2.0 & 3.0 & 4.0 & 5.0 & 6.0 & 7.0 & 8.0 & 9.0 \\
\hline 2.0 & $\begin{array}{l}0,2 \\
3,1 \\
0\end{array}$ & $\begin{array}{l}0,4 \\
0,0\end{array}$ & $\begin{array}{l}0,7 \\
1,1\end{array}$ & $\begin{array}{l}0,9 \\
2,3\end{array}$ & $\begin{array}{l}0,1 \\
3 \\
0,1 \\
\end{array}$ & $\begin{array}{l}0,1 \\
5 \\
1,0 \\
\end{array}$ & $\begin{array}{l}2,16 \\
0,1\end{array}$ & $\begin{array}{l}3,18 \\
0,0\end{array}$ & $\begin{array}{l}4,19 \\
0,0\end{array}$ & $\begin{array}{l}5,20 \\
0,0\end{array}$ \\
\hline 3.0 & $\begin{array}{l}0,2 \\
3,1 \\
0\end{array}$ & $\begin{array}{l}0,4 \\
0,0\end{array}$ & $\begin{array}{l}0,7 \\
1,1\end{array}$ & $\begin{array}{l}0,1 \\
2 \\
0,0\end{array}$ & $\begin{array}{l}0,1 \\
5 \\
0,0\end{array}$ & $\begin{array}{l}2,1 \\
7 \\
0,0\end{array}$ & $\begin{array}{l}3,18 \\
0,0\end{array}$ & $\begin{array}{l}5,20 \\
0,0\end{array}$ & $\begin{array}{l}7,22 \\
0,0\end{array}$ & $\begin{array}{l}8,23 \\
0,0\end{array}$ \\
\hline 4.0 & $\begin{array}{l}0,2 \\
3,1 \\
0\end{array}$ & $\begin{array}{l}0,4 \\
0,0\end{array}$ & $\begin{array}{l}0,9 \\
0,0\end{array}$ & $\begin{array}{l}0,1 \\
4 \\
0,0\end{array}$ & $\begin{array}{l}1,1 \\
6 \\
0,0\end{array}$ & $\begin{array}{l}3,1 \\
8 \\
0,0\end{array}$ & $\begin{array}{l}5,20 \\
0,0\end{array}$ & $\begin{array}{l}7,22 \\
0,0\end{array}$ & $\begin{array}{l}9,24 \\
0,0\end{array}$ & $\begin{array}{l}11,2 \\
6 \\
0,0\end{array}$ \\
\hline 5.0 & $\begin{array}{l}0,2 \\
3,1 \\
0\end{array}$ & $\begin{array}{l}0,5 \\
1,2\end{array}$ & $\begin{array}{l}0,8 \\
0,0\end{array}$ & $\begin{array}{l}0,1 \\
5 \\
0,0 \\
\end{array}$ & $\begin{array}{l}2,1 \\
7 \\
0,0 \\
\end{array}$ & $\begin{array}{l}4,1 \\
9 \\
0,0 \\
\end{array}$ & $\begin{array}{l}7,22 \\
0,0\end{array}$ & $\begin{array}{l}9,24 \\
0,0\end{array}$ & $\begin{array}{l}11,2 \\
6 \\
0,0\end{array}$ & $\begin{array}{l}13,2 \\
8 \\
0,0\end{array}$ \\
\hline 6.0 & $\begin{array}{l}0,3 \\
1,5\end{array}$ & $\begin{array}{l}0,5 \\
0,0\end{array}$ & $\begin{array}{l}0,1 \\
2\end{array}$ & $\begin{array}{l}0,1 \\
6\end{array}$ & $\begin{array}{l}3,1 \\
8\end{array}$ & $\begin{array}{l}6,2 \\
1\end{array}$ & $\begin{array}{l}7,22 \\
0,0\end{array}$ & $\begin{array}{l}10,2 \\
5\end{array}$ & $\begin{array}{l}16,2 \\
7\end{array}$ & $\begin{array}{l}19,2 \\
9\end{array}$ \\
\hline
\end{tabular}


Application of Quick Switching System-1 with Single Sampling Plan

\begin{tabular}{|l|l|l|l|l|l|l|l|l|l|l|}
\hline & & & 0,0 & 0,0 & 0,0 & 0,0 & & 0,0 & 0,0 & 0,0 \\
\hline 7.0 & 0,3 & 0,1 & 0,1 & 0,1 & 2,1 & 4,1 & 6,21 & 7,22 & 16,2 & 19,2 \\
& 1,2 & 0 & 3 & 5 & 6 & 9 & 0,0 & 0,0 & 7 & 9 \\
& & 0,0 & 0,0 & 0,0 & 0,0 & 0,0 & & & 0,0 & 0,0 \\
\hline 8.0 & 0,4 & 0,5 & 0,1 & 0,1 & 3,1 & 4,1 & 9,21 & 7,22 & 18,2 & 22,3 \\
& 0,0 & 0,0 & 3 & 5 & 6 & 9 & 0,0 & 0,0 & 5 & 7 \\
& & & 0,0 & 0,0 & 0,0 & 0,0 & & & 0,0 & 0,0 \\
\hline 9.0 & 0,4 & 0,1 & 0,1 & 0,1 & 3,1 & 4,1 & 11,2 & 10,2 & 24,3 & 29,3 \\
& 0,0 & 0 & 3 & 5 & 6 & 9 & 2 & 5 & 6 & 0 \\
& & 0,0 & 0,0 & 0,0 & 0,0 & 0,0 & 0,0 & 0,0 & 0,0 & 0,0 \\
\hline
\end{tabular}

